\title{
A INFLUÊNCIA DA IGREJA NO CASAMENTO ENTRE BEATRIZ DE CASTELA E O PRÍNCIPE AFONSO: PODER, POLÍTICA E RELIGIOSIDADE
}

\section{PRISCILA CARDOSO SILVA*}

Resumo: o artigo tem como propósito central prestar contribuições às questões de poder relativas ao período da Baixa Idade Média, evocando a imagem de Beatriz de Castela, uma rainha pouco conhecida nas historiografias lusitana e, especialmente, brasileira. Ao tomar como fonte a Crônica de D. Dinis, elaborada entre o final do século XV e o início do século XVI por Rui de Pina, este trabalho analisa um discurso de exaltação régia que possui como narrativa principal o reinado do sogro da castelhana, o rei D. Dinis de Portugal, situado historicamente entre a segunda metade do século XIII e as primeiras décadas do século XIV. Buscando focar na representação do casamento entre Beatriz e Afonso, construída pelo cronista durante o desenvolvimento de suas obras e também marcada por sua influência cristã na historiografia, o artigo pretende, então, ajudar a compreender qual imagem de matrimônio real se desejava, no período em que escrevia o autor, que permanecesse na memória dos portugueses.

Palavras-chave: Portugal; Idade Média; Crônica de D. Dinis; Beatriz de Castela; Matrimônio.

\section{The influence of the Church in the marriage of Beatrice of Castile and the prince Afonso: power, politics and religiosity}

\begin{abstract}
This article has as central purpose to give contributions to the power questions related to the period of the Late Middle Ages, evocating the image of Beatrice of Castile, a little-known queen in the Lusitanian and, especially, Brazilian historiographies. Taking as source the Chronicle of D. Dinis, developed between the end of the fifteenth century and the beginning of the sixteenth century by Rui de Pina, this paperwork analyses a royal exaltation discourse that has as principal narrative the reign of the father-in-law of the Castilian, the king D. Dinis of Portugal, historically situated between the second half of the thirteenth century and the first decades of the fourteenth century. Seeking to focus in the representation of the marriage between Beatrice and Afonso, constructed by the chronicler during the development of his works and also marked by its Christian influence in historiography, the article, then, intends to help to understand which image of the royal matrimony it desired, in the period when the author wrote them, to remain in Portuguese memories.
\end{abstract}

Key words: Portugal; Middle Ages; Chronicle of D. Dinis; Beatrice of Castile; Matrimony.

Beatriz de Castela tinha cerca de quatro anos de idade quando o Tratado de Alcanices foi acordado. Com a sua assinatura, no ano de 1297, deixou então de conviver com seus numerosos irmãos ${ }^{1}$ em Castela para morar em Portugal e ser criada pelos

\footnotetext{
${ }^{1}$ Da união entre Sancho IV e Maria de Molina, nasceram sete filhos no total. Por ordem de nascimento,
} 
reis lusitanos D. Dinis e D. Isabel, que viriam a ser seus sogros. María Jesús Fuente, talvez por sua nacionalidade, enfatizara o papel da mãe de Beatriz na negociação:

Pero antes de buscar ese nuevo marido para Isabel, que en 1296 contaba ya 13 años de edad, la reina María se preocupó de negociar nuevos enlaces matrimoniales con otro reino peninsular, el reino de Portugal. De esa manera pretendía ganarse a um enemigo, y destruir la coalición en la que los portugueses participaban. La negociación con la corte portuguesa tuvo lugar en 1297, y de ella salió un doble boda, la del rey menor Fernando IV con Constanza de Portugal, y la de la princesa Beatriz de Castilla con Alfonso de Portugal. La princesa Beatriz, con cuatro años de edad fue transladada a la corte portuguesa, donde unas manos de santa, la reina santa Isabel de Portugal, tendríam la tarea de educarla (Fuente, 2004, p. 273).

Preparando-se para cumprir o papel de rainha de Portugal ao tornar-se esposa do futuro rei D. Afonso IV, Beatriz fora então criada fora de Castela desde a mais tenra idade - e por propósitos políticos. A pesquisadora Ana Rodrigues Oliveira ressalta que, a essa época, não era incomum o fato de as meninas novas abandonarem a vivência com a corte de seu reino de origem a fim de aprontarem-se para exercer atribuições de esposas e mães. ${ }^{2}$ Com isso, rompiam bruscamente com seus laços familiares para preencher expectativas dinásticas ou linhagísticas, em uma lógica que visava - para

tem-se, em primeiro lugar Isabel, que nasceu na vila de Toro no ano de 1282. Essa infanta ficou aos cuidados de sua ama, Maria Fernández Coronel, que foi aia de sua mãe. O seu acordo matrimonial foi estabelecido com Jaime II, rei de Aragão. Porém, com a morte de Sancho IV, o monarca aragonês rompeu o compromisso e devolveu a princesa a Castela. A infanta então casou, em 1310, com João III, duque da Bretanha, de quem não teve sucessão. Fernando, o desejado filho varão e herdeiro do trono de Castela, nasceu em Sevilha a 6 de Dezembro de 1285. Já o terceiro filho foi o infante Afonso, que nasceu no início do ano de 1286 em Valladolid e pereceu com cinco anos na mesma cidade. O quarto descendente teve o nome de Henrique e veio ao mundo em Vitoria, no ano de 1288, tendo falecido em 1299. Em Valladolid, a rainha deu à luz o seu quinto filho, o infante Pedro, no ano de 1290, falecido em 1319. Esse príncipe casou-se, em 1311, com Maria - filha de D. Jaime II e infanta de Aragão - de quem teve uma filha, Branca. No ano de 1292 nasceu, em Sevilha, o infante Filipe, que casou com Margarida de Lacerda, neta de D. Fernando de Lacerda. Filipe faleceu em 1359, sem sucessão. A última filha do matrimônio dos reis castelhanos foi a infanta Beatriz.

2 A esse costume, dá-se o nome de "patrilocalidade", difundido no final da Idade Média, o qual garantia aos homens e rapazes disponíveis para o casamento o ambiente social a que estavam habituados e retirava das mulheres essa prerrogativa, pois as jovens noivas eram enviadas para a esfera de influência da família do futuro marido. Isso é, prometido o matrimônio, procedia-se a transferência da noiva, geralmente ainda criança. Essa transferência poderia ser para um convento ou para a corte ou casa do futuro cônjuge. Porém, essa retirada das jovens noivas de seus ambientes de origem nem sempre resultava em vivências negativas, pois a convivência com a futura família desde muito jovem poderia criar uma familiaridade positiva para a noiva, conforme será observado no caso de Beatriz. Sobre a "patrilocalidade", ver TREVISAN, M. B. 2012. Construção de identidades de gênero e afirmação régia: os casais da realeza portuguesa entre os séculos XIV e XV a partir das crônicas de Fernão Lopes. Niterói, RJ. Dissertação (Mestrado em História Social), Universidade Federal Fluminense, pp. 37-38 e passim. 
além das alianças políticas e especialmente para uma rainha - uma "rápida produção de filhos" (Oliveira, 2010, p. 216).

Cláudia Opitz, por sua vez, atenta que a idade reduzida das moças minimizava a possibilidade de elas conseguirem impor sua vontade na celebração do casamento. Dessa forma, ter uma idade mais elevada antes do casamento era uma condição para que a mulher melhorasse sua "posição negociadora" no âmbito conjugal, ainda que isso não fosse o suficiente para defender seus próprios interesses (Optiz, 1990, pp. 362-365).

Inseridas, portanto, em um contexto de sociedade calcada pelos laços de parentesco - ou em uma cristandade medieval na qual as relações pessoais são em grande parte definidas através desses laços, conforme assume Jerôme Baschet (Baschet, 2006, p. 448) - mulheres como Beatriz de Castela fazem parte de uma teia de regras que define a filiação e rege as práticas de alianças. Anita Guerreau-Jalabert afirma que o parentesco envolve a consanguinidade e a aliança, sendo a primeira correspondente aos elos entre dois indivíduos, dos quais um descende do outro ou reconhecem um ascendente comum e a segunda traduzida como a forma pela qual os grupos de consanguíneos são ligados entre si pela aliança do matrimônio. Segundo a autora, a consanguinidade é "definida por regras de natureza social e não biológica, rege o recrutamento dos grupos de parentes, mas também a transmissão dos bens materiais e simbólicos" (Guerreau-Jalabert, 2002, p. 322).

Dissertando sobre a relação entre acordos políticos e casamentos reais durante o período da Idade Média, o historiador José Carlos Gimenez ressalta que os monarcas acabavam por transformar seus filhos, irmãos, sobrinhos e netos em indivíduos imprescindíveis no processo de negociação (Gimenez, 2012, p. 99). Fruto mais da vontade política que do desejo da infanta, a ida de Beatriz foi retratada pelo cronista Rui de Pina como o início de um comportamento virtuoso na nova corte:

Acabadas estas couzas ElRei D. Fernando se partio Dalcanizes com ha Rainha sua molher, e ElRei D. Diniz trouxe logo pera Portugal consigo, e por Esposa do Ifante D. Affonso seu filho, ha Ifante Dona Breatis irmãa delRei D. Fernando, filha delRei D. Sancho, e da Rainha Dona Maria, ha quaal seendo ainda mui moça, andou mui honradamente em caza delRei D. Diniz, em quanto ambos eraõ soomente cazados por palavras de futuro, cujo prometimento se fez por elles em Coim- 
bra na era de mil trezentos e sete annos [...] (Pina, 1912, vol. 1, pp. 64-65).

Ser uma futura rainha de origem castelhana em um reino que frequentemente entrava em guerra com Castela poderia ter Ihe rendido desaprovações e má fama, porém o cronista sugere que Beatriz conseguiu se adaptar rapidamente, recebendo por ele uma imagem de mulher honrada ainda quando o autor narrava acontecimentos decorrentes do casamento. Cabe esclarecer que, aqui, o vocábulo "imagem" acompanha a concepção dos historiadores dos últimos anos de associá-lo não unicamente a valores estéticos, mas ao funcionamento social e às funções ideológicas. Essa compreensão remonta sua origem terminológica do latim imago, utilizada na própria concepção medieval do mundo e do homem que, segundo Jean-Claude Schmitt:

[...] remete não somente aos objetos figurados (retábulos, esculturas, vitrais, miniaturas, etc.), mas também às "imagens" da linguagem, metáforas, alegorias, similitudines, das obras literárias ou da pregação. Ela se refere também à imaginatio, às "imagens mentais" da meditação e da memória, dos sonhos e das visões, tão importantes na experiência religiosa do cristianismo [...] (Schmitt, 2002, p. 592).

Logo, as imagens medievais expressam um mundo cristão que não é neutro tampouco sem hierarquia. Por conseguinte, o imaginário de corte sobre a mulher no final do medievo então se refere à produção de imagens e símbolos - uma vez que a imagem não é necessariamente figurativa, mas alegórica-simbólica (Schmitt, 2002, p. $595)$ - referentes aos ideais femininos dentro desse grupo social. Na verdade, a pesquisa cujo artigo em questão se origina concebe a corte régia mais do que uma parte da sociedade ou uma definição simples de "conjunto de pessoas que cercam o príncipe" (Guenée, 2002, p. 269).

Como pontuou Oliveira Marques, as cortes régias eram um dos meios mais importantes de cultura na Idade Média. Centro de convívio da elite do reino, permitiam não só o afinamento do idioma e das formas de comunicação através das regras de etiqueta e conversação polida, como também numerosas formas de expressão cultural: produção de livros, "saraus literários" com leituras em voz alta, dança, canto, teatro e um desporto organizado (caças, justas, torneios). Além disso, ocorriam ricas trocas culturais, por meio do convívio com pessoas vindas de outros reinos, das atividades 
ligadas ao mecenato e acolhimento de autores de vários gêneros, do planejamento de guerras e organização de expedições marítimas e de toda a estrutura administrativa e burocrática subjacente (Oliveira Marques, 1987, pp. 425-426). Por fim, cabe alertar o papel da corte como lugar de piedade, pois, segundo Guenée, não se concebia uma corte sem esse centro de devoção que era a capela, tanto mais santa quanto mais prestigiosas fossem as relíquias que abrigava (Guenée, 2002, p. 277).

Por sua vez, a corte pode também ser entendida como centro político e lugar do crescente poder régio a partir do período final do medievo. Em seu seio estavam acopladas, desde o século XIII, instituições dedicadas à administração, cujos contornos pouco a pouco se definiam e cuja importância aumentava, dando origem ao Parlamento. De acordo com Armindo de Sousa:

\begin{abstract}
A instituição parlamentar medieval portuguesa só existia realmente enquanto funcionava, isto é, foi uma instituição iterativa, identificada com reunião ou assembleia actuante. Nascia e renascia todas as vezes que o Poder, convocados os membros dela, tratava com eles os negócios que entendia propor-lhes ou outros que aceitava discutir. Todavia, pode e deve falar-se do parlamento medieval como uma instituição virtualmente permanente (Sousa, 1992, p. 510).
\end{abstract}

A corte, então, constitui uma encruzilhada de diversos poderes, polarizando conflitos e alianças que organizam uma sociedade política. Ademais, Rita Costa Gomes pondera que a corte "[...] é o local onde emerge a representação mesma da unidade do reino, onde se fabrica o discurso da sua história, onde se manifesta pela palavra e pela ação a sujeição da comunidade inteira a um homem, a uma dinastia" (Gomes, 1995, p. 4).

No intuito de compreender a expressão "palavras de futuro" mencionada na supracitada passagem da Crônica de D. Dinis, importa identificar as principais etapas que conduzem a oficialização de um casamento régio medieval entre os mais jovens. Opitz lembra que os noivos pouco decidiam sobre seus próprios casamentos (Opitz, 1990 , p. 362). Enquanto eles eram incapazes de cumprir a etapa do consentimento mútuo - uma vez que a lei canônica não reconhecia uma aliança matrimonial entre menores de sete anos - o acordo entre seus pais permanecia na promessa. Através dessas palavras, estabeleciam-se direitos e deveres recíprocos entre ambas as partes e 
firmava-se uma espécie de noivado.

Então, para que o status de matrimônio por "palavras de futuro" fosse superado e o de "palavras de presente" legitimado, os noivos confirmavam a sua maturidade professando a aceitação do outro. Contudo, a idade mais conveniente para o consentimento dos noivos era em torno dos doze anos para a mulher e dos catorze anos para o homem, quando finalmente eram realizadas as bodas públicas, ou seja, a cerimônia propriamente dita. ${ }^{3}$ Por volta do ano de 1307 , Beatriz possuía cerca de catorze anos e Afonso já alcançava os dezesseis, de forma que o casamento poderia ser considerado válido e pronto para a consumação (com objetivo de procriação). ${ }^{4}$

Embora a sequência pareça simples, as "palavras de futuro" elucidadas na crônica evocam outra problemática concernente aos matrimônios medievais: mais do que priorizar interesses políticos e estabelecer o destino de jovens com pouquíssima idade - impedindo-os de oficializar a união de imediato - os casamentos muitas vezes sofriam um retardo burocrático que independia das decisões das partes envolvidas. Desde o IV Concílio de Latrão, em 1215, o direito canônico passava a proibir matrimônios até o quarto grau de consanguinidade e afinidade no objetivo de evitar a prática do incesto. ${ }^{5}$ Ademais, Lourenço reforça que, fazendo do casamento um de seus sacramentos

\footnotetext{
${ }^{3}$ A partir das reflexões sobre os estudos de pesquisadores como Nieto Soria, leda Avênia de Mello entende que o termo cerimônia, que pode ser aplicável às bodas públicas medievais, "[...] pode ser definido como a manifestação de sentimentos, de atitudes em comum através de ações mais ou menos formalmente ordenadas e de natureza essencialmente simbólica em ocasiões apropriadas. 0 termo pode, mas não necessariamente, conter orientações para objetos, orientações empíricas ou nãoempíricas capazes de inspirar atitudes de lealdade, respeito e reverência" (MELLO, 2006, p. 5). Christopher Brooke aponta que a Igreja sempre havia desejado que as uniões fossem marcadas por uma cerimônia eclesiástica. Ainda nos finais do século XI e XII, poder-se-ia encontrar rituais totalmente integrados, em que todos os elementos (troca de ofertas, troca de promessas, benção sacerdotal, missa nupcial, benção da câmara nupcial) estavam reunidos. Estes rituais estenderam-se lentamente a toda a cristandade ocidental por meio de esforços constantes para levar os noivos a celebrarem publicamente seu matrimônio diante da igreja. Configurava-se assim o casamento público: in facie ecclesiae (Brooke, 1989, p. 125).

${ }^{4}$ Segundo Marcello Caetano, embora o matrimônio resulte per solum consensu (por consentimento acima de tudo), ele só se torna perfeito e indissolúvel (rato) quando consumado por cópula carnal entre os cônjuges. Ver CAETANO, M. 1985. História do Direito Português (1140-1495). Lisboa, Verbo, pp. 429- 431. A data de 1307 surge na Crônica de D. Dinis, porém autores portugueses costumam afirmar que Afonso e Beatriz casaram-se dois anos depois, em 1309. Ver, como exemplo, SERRÃO, J. (dir.). 1984. Dicionário de História de Portugal. Porto, Figueirinhas, vol. 1, p. 318. Prefere-se, aqui, utilizar a datação contida na fonte.

${ }^{5}$ Atenta-se para o fato de que uma política matrimonial canônica consistente começa a ser delineada desde os séculos XI e XII. Fora nesse período que, segundo Brooke, passa a existir uma liturgia do casamento, a crescente afirmação da Igreja pela total jurisdição sobre o matrimônio e a tentativa de dar uma forma clara do que poderia ser compreendido como um casamento legal e válido (Brooke, 1989, p. 59).
} 
principais, a Igreja procurava impor o seu modelo "como forma de enquadrar e controlar as alianças suscitadas pelo parentesco" (Lourenço, 2008, p. 352). Assim, para um casamento desse tipo ser considerado válido, era necessário conseguir uma autorização papal.

A importância de bulas de dispensa de parentesco em sociedades que valorizavam a tradição das linhagens, portanto, revelava uma submissão ainda mais forte aos valores e normas da Igreja. No caso do reino português e ainda no início do século XX, Fortunato de Almeida escreve, no prefácio do seu magistral livro História da Igreja em Portugal, que:

Seria supérfluo encarecer a necessidade de uma obra em que se estudasse a história da Igreja em Portugal, quando todas as manifestações da vida colectiva do país se encontraram quase sempre e profundamente influenciadas pelas ideias religiosas e pelo espírito das instituições eclesiásticas. Pretender estudar a evolução histórica do povo português, abstraindo prèviamente da sua vida religiosa e da missão do clero regular e secular, seria o mesmo que tentar compreender o mecanismo circulatório fora dos vasos sanguíneos. Por isso e por não se ter estudado devidamente a história eclesiástica de Portugal, muitas páginas da nossa história política e social não foram ainda compreendidas, [...] (Almeida, 1967, prefácio).

Segundo o autor, quando a monarquia portuguesa é fundada em meados do século XII, os papas já exerciam na Europa uma espécie de supremacia política reconhecida pelos reis. Embora defenda que esse poder foi largamente exercido com "consentimento e aplauso" desde então - posto que as consciências piedosas da Idade Média, em vez de considerarem a sujeição ao Papa como condição humilhante viam nela, pelo contrário, um favor e privilégio para desejar (Almeida, 1967, pp. 83 e 86) - o presente trabalho enfatiza que foi mais por volta do final do século XIII que o poder papal estendeu-se por todo o Ocidente, reforçado por uma série de medidas que almejavam um controle sobre atitudes, consciências e mentalidades. Em contrapartida, Maria Isabel García reforça que:

Al mismo tiempo, la iglesia iría arbitrando una serie de fórmulas dispensatorias, pero ya bajo su control, que de manera excepcional admitía matrimonios entre parientes próximos o incluso separaciones em caso de matrimonios sin descendencia, como, por ejemplo, ocurrió con la separación de Urraca de Castilla y Alfonso el batallador de 
Aragón [...] (García, 2001, p. 11).

No casamento entre Beatriz e Afonso, acordado em 1297, a autorização papal era essencial, particularmente, devido as suas posições de futuros monarcas; caso contrário, a legitimidade de sua dinastia entraria em risco, visto que os sucessivos casamentos entre membros de suas famílias os incluíam na proibição do IV Concílio de Latrão. Afinal, Beatriz era neta do rei castelhano Afonso $X$, enquanto o infante português era bisneto do mesmo por via de sua avó paterna Beatriz Guillén de Gusmão, bastarda de Afonso X e casada com D. Afonso III de Portugal.

Além disso, era providencial insistir em uma petição de legitimidade, pois até o ano de Alcanices, tanto Beatriz quanto seu irmão Fernando ainda não haviam sido considerados filhos legítimos, prejudicando a sucessão do trono. Isso se dava pelo fato de seus pais, Sancho IV de Castela e Maria de Molina, serem parentes de terceiro grau e, consequentemente, supostamente impossibilitados de contrair matrimônio à luz do direito canônico.

As solicitações ao papa - a dispensa de parentesco e a petição de legitimidade - só foram atendidas no ano de 1301, quando a rainha Maria angariou, através de contribuições das cidades, empréstimos e rendimentos de seu patrimônio particular, uma soma de dez mil marcos de prata para acompanhar os pedidos (Fuente, 2004, p. 273). Mesmo assim, em 1301 Beatriz ainda nem havia completado os dez anos, de modo que o casamento só foi oficializado posteriormente. De qualquer forma, com a assinatura do Tratado de Alcanices, D. Dinis pusera logo em prática os acordos prématrimoniais que regulam o destino e gestão de bens, tais como a carta de arras. Segundo Lourenço:

A carta de arras, verdadeiro pacto social e econômico, era celebrada [...] quando o enlace se realizava entre menores e podia ter lugar antes da boda. Assim, o rei português entregava a D. Beatriz o senhorio de Évora, Vila Viçosa Vila Real e Gaia com Vila Nova, perfazendo uma renda anual de seis mil libras da moeda velha de Portugal, [...]. A futura rainha ficava assim, a deter o senhorio das ditas terras com todos os seus direitos, que funcionavam como uma espécie de "seguro", uma vez que, na senda da tradição do direito visigótico, as arras eram propriedade da mulher e protegiam-na materialmente no caso dos esposos se separarem e anularem o matrimônio, mas também 
em caso de viuvez ou repúdio (Lourenço, 2008, p. 354). ${ }^{6}$

Observa-se aqui a coexistência dos direitos canônico e germânico em um mesmo evento. Afinal, Gama Barros lembra que o código visigótico foi o primeiro e mais antigo monumento da legislação geral primitiva portuguesa (Barros, 1885 , p. 3), ${ }^{7}$ mas igualmente que o estudo do direito canônico foi estabelecido ainda nos primeiros estatutos na universidade de Coimbra, em 1309 (Barros, 1885, p. 59). De maneira mais geral, Fortunato de Almeida assegura que:

Tanto as monarquias cristãs como os moçárabes conservaram as tradições do código visigótico acerca do predomínio das leis eclesiásticas, que a cada passo aparecem citadas nas escrituras de contratos e nos processos e decisão dos litígios, e até foram seguidas na ordem a formalidade dos processos (Almeida, 1967, p. 158).

Jorge Osório, por sua vez, afirma que, durante o reinado de D. Dinis de Portugal, as bases da administração interna foram contextualizadas pela "difusão crescente da influência do direito romano, que será factor fundamental para a estruturação do Estado e para o progressivo afastamento de uma configuração estritamente senhorial" (Osório, 1993, p. 19). Outro exemplo de utilização da autoridade real de maneira a contrariar os poderes locais e conter seus abusos deu-se com a repetida e sistemática realização de inquirições gerais, a partir de 1284, no intuito tanto de fazer o levantamento das terras e rendas do rei quanto de pretender fixar os limites das honras, das terras imunes que eram detidas pelos senhores e de em quais poderiam exercer seus direitos senhoriais como cobrar rendas, exigir serviços e aplicar a justiça. Mais do que objetivar afirmar-se politicamente através da busca de consolidação de aspectos administrativos e diplomáticos, o reino português do final do século XIII era caracterizado por um sincretismo cultural que refletia em suas próprias decisões.

Um exemplo refere-se ao cultivo da poesia galego-portuguesa, herdada por D. Dinis especialmente através de seu avô Afonso X de Castela, mas já considerada uma

\footnotetext{
${ }^{6}$ D. Dinis também entregou outras terras a Afonso em decorrência de seu casamento, tais como os senhorios de Viana, Terena, o castelo de Ourém e provavelmente Armamar, além de uma quantia para manter-se. De acordo com Bernardo Vasconcelos e Sousa, eram as terras concedidas em arras pelo rei português a sua futura nora somadas àquelas doadas ao infante que constituíram a base material em que assentaria a vida do casal (Sousa, 2009, p. 32).

${ }^{7}$ Outra herança germânica conservada no período foi a representação do clero em cortes, que tinha sua origem nos concílios da monarquia visigótica (Almeida, 1967, p. 158).
} 
estratégia para Afonso III na medida em que era cada vez mais difundida na corte, corroborando para a "domesticação da fidalguia e favorecendo uma nobreza de corte, submissa e fiel" (Osório, 1993, p. 21). Trata-se de uma corte "relativamente ilustrada" (Almeida, 1967, p. 202), por meio da qual seu rei aos poucos conseguia fortalecer sua própria autoridade. Foi em 1290, no reinado de D. Dinis, por exemplo, que se criou o chamado "Estudo Geral" na cidade de Coimbra, que nada mais seria do que a pedra fundamental da atual universidade.

Tal acontecimento não passou despercebido a Rui de Pina - que relatou a iniciativa do rei, enaltecendo a sua capacidade de realizar obras louváveis (Pina, 1912, vol. 2, pp. 85-87) - nem a Gama Barros, que através de uma análise da diversidade legislativa no período dionisino classificou a criação da universidade, local onde se mandavam ensinar as leis, como a manifestação do desenvolvimento intelectual da época (Barros, 1885, pp. 67-68). De fato, durante o reinado de D. Dinis, é possível constatar uma preocupação tanto com a maneira de legislar quanto com o modo de governar o reino. O clero, por exemplo, ao mesmo tempo em que tinha a maioria de seus privilégios garantida pela própria tradição legislativa - "vê-se da primeira lei das cortes de Coimbra de 1211, em que se determinou que as leis e constituições reais não seriam contrárias aos cânones e direitos da Igreja" (Almeida, 1967, p. 158) ${ }^{8}$ - conviveu com leis contra a amortização ${ }^{9}$ e a vantagem do foro eclesiástico. ${ }^{10}$

Contudo, tais medidas adotadas pelo rei lusitano não representavam uma efetiva ameaça aos interesses do papa, pois as providências adotadas por D. Dinis para extinguir os abusos em matéria de privilégios eclesiásticos estavam de acordo com as ideias do pontífice, desde que se respeitasse os casos em que o direito canônico expressamente os reconhecia (Almeida, 1967, pp. 159-160). Fortunato de Almeida interpreta que se por um lado o clero teve que desistir de aspirações demasiado ambiciosas, por outro viu melhor definidos e mais garantidos seus próprios direitos (Almeida, 1967, p. 202).

\footnotetext{
${ }^{8}$ Partindo da mesma reflexão, o autor alega que da vigência do direito canônico e da autoridade que tinham as determinações dos papas resultaram imensas vantagens para o clero, porque as leis dos monarcas regulavam-se geralmente pelas decisões dos cânones e não deixavam de beneficiar e respeitar a Igreja.

9 Citam-se, a fins exemplificativos, as leis de 10 de julho de 1286, 21 de março de 1291, 7 de abril de 1295 e 30 de julho de 1305, todas expedidas no período do reinado em pauta.

${ }^{10}$ Para exemplificar mais uma vez, tem-se a lei de 9 de agosto de 1305.
} 
Em um dos capítulos que Rui de Pina trata sobre a discórdia entre o sogro de Beatriz e seu marido, é interessante observar a parcialidade da escrita do cronista em prol do rei lusitano e contra o infante. Mesmo quando o primeiro comete um erro que parece ameaçar a continuidade da própria linhagem - o adultério - exalta-se sua figura de bom pai e avô:

[...] e assi em todalas couzas, que occurriam se vio que [D. Dinis] ho honrava, e estimava muito, e tinha cuidado de lhe criar seus filhos [os filhos de D. Afonso], porque jaa atee este teempo elle ouvera ho Ifante $D$. Afonso, que menino faleceu em Penella, e assi ouve ho Ifante D. Diniz, que seu avoo ElRei D. Diniz com grande amor criava em sua caza, e nella faleceu moço, porque ElRei foi tam anojado, e triste que nom sabia, nem podia com nenhuma couza seer ledo, nem consolado, e em tanto estremo sentio ha morte deste seu neto, que ho Papa Ihe escreveo sobresso hum Breve de consolaçam, cheio de muita prudencia, e graãdes confortos (Pina, 1912, vol. 2, p. 107).

Aqui, palavras derivadas dos verbos honrar, estimar, cuidar, amar, criar e sentir qualificam positivamente o rei D. Dinis. Todavia, importa acrescentar que para o amor de um homem ser considerado efetivamente uma virtude, deveria seguir as prescrições e fórmulas apresentadas pelos teóricos medievais. Elas inferem, por exemplo, que o amor de um pai é nobre quando tende mais para o aperfeiçoamento de sua alma do que para o bem-estar do corpo. Posto que o homem seja mais racional do que a mulher, seu ato de amar já se encontra em um nível intrinsecamente mais virtuoso. ${ }^{11}$

A presença e preocupação do papa na passagem, ${ }^{12}$ por sua vez, sugere uma proximidade também com a autoridade eclesiástica e, principalmente, com os preceitos cristãos. Necessário faz-se lembrar do rei enquanto pessoa inserida na categoria de "cristão":

\footnotetext{
${ }^{11}$ Sobre as diferenças entre o amor de um homem e o de uma mulher, ver Vecchio. 1990, p. 164-165.

${ }^{12}$ Os papas surgem correntemente na Crônica de D. Dinis, especialmente emitindo pronunciamentos sobre a situação portuguesa, nomeadamente por parte do rei. Rui de Pina inclusive transcreve a tradução de uma suposta carta do chefe da Igreja a partir de 1316, João XXII (1249-1334), claramente favorável ao monarca de Portugal ao repreender as ações de Afonso, mas procurando estabelecer a paz diante de uma guerra civil. Tal tradução acaba por dotar-se de um cunho acusatório e de argumentação bastante similar às que surgem ao longo da crônica em voz de D. Dinis. Parece claro, então, que a inserção dessa carta pontifícia em específico na narrativa possui o objetivo de promover a condenação do infante e de pôr em destaque as razões do rei, legitimando sua perspectiva (Pina, 1912, vol. 2, p. 126 e pp. 138-143). No entanto, as pesquisas de Fernando Félix Lopes e Bernardo Vasconcelos e Sousa demonstram não apenas que tais correspondências pontifícias existiram de fato quanto que eram recompensadas ou de certa forma motivadas por alguns milhares de florins enviados pelo rei português aos papas. Ver: Sousa, 2009. p. 59-62.
} 
[...] é que os príncipes têm duas qualidades; são ao mesmo tempo cristãos e chefes de Estado. Como cristãos, os príncipes encontravam-se naturalmente sujeitos às mesmas obrigações que os outros fiéis, e, se cometessem crimes, deviam incorrer nos mesmos castigos (Almeida, 1967, p. 83).

Igualmente conforme Bernard Guenée, a tradição antes de tudo pedia ao príncipe que praticasse as virtudes que a Igreja exigia a qualquer seguidor de Cristo (Guenée, 1981, p. 115). É extremamente difícil separar as virtudes cristãs do rei enquanto pessoa do rei em seu ofício de governante, pois as concepções cristãs estão em íntima conexão com as idealizações da função régia. Aliás, como princípio geral e a partir das Escrituras, tem-se que Deus é o rei dos reis, constituindo o ideal monárquico maior. Virtudes à parte, a crônica enfatiza, ao contrário, a desobediência de Afonso:

\begin{abstract}
E segundo ho que acho, e pude comprender, tres razoens ouve, e todas sem cauza, nem rezaõ, porque ho Ifante D. Affonso se moveo ha esta sua desobediencia contra seu padre, das quaaes ha primeira foi em Beja, por sentir que ElRei D. Diniz queria grande beem ha D. Affonso Sanches, e aho Conde D. Joaõ Affonso seus filhos naturaaes, hos quaaes segundo se acha nom serviam, nem catavaõ aho Ifante como elle desejava, e merecia, e deste conto nom era ho Conde D. Pedro tambem seu irmaão bastardo, e de todos hos bastardos ho mais velho, porque sempre seguio ha parte do Ifante, e por esso foi ha requerimento de $\mathrm{D}$. Affonso Sanches desterrado de Portugal pera Castella, e todas suas teerras, e fazendas tomadas, [...], e ha segunda cauza foi ha grande cobiça, e desordenado desejo, que sempre teeve de aver, e cobrar pera si has riquezas, e tezouros del Rei seu padre, e ha terceira por querer, que em toda maneira EIRei deixasse, e tirasse de si ha Justiça, e Governança do Regno, e livremente deixasse ha elle (Pina, 1912, vol. 2, pp. 108-109).
\end{abstract}

Na passagem supracitada, os filhos de D. Dinis primeiro foram caracterizados como "naturais" para depois, quando houve a necessidade de revelar quem era o conde D. Pedro, serem mencionados como "bastardos". Embora ambas as palavras signifiquem que os filhos não provêm do matrimônio, a primeira descrição constitui mais um sentido de eufemismo do que propriamente uma explicação. Ademais, D. Afonso interpreta o papel de vilão por contrariar o pai, e, ao mesmo tempo, o rei, faltas consideradas gravíssimas em uma comunidade cristã calcada nas relações de parentesco e cada vez mais fundamentada pelo poder monárquico.

Se à sociedade narrada atribuem-se tais características, no contexto social em 
que escreve Rui de Pina a majesta - princípio de origem romana retomado somente a partir do século XIII - justifica, juntamente com a própria noção de poder real mais sólida e constante, a difusão do crimen majestatis, o crime de lesa-majestade. ${ }^{13}$ Obviamente que, se a intenção era de evocar uma tradição memorialística, o cronista não elevaria as supostas atitudes do futuro monarca a tal ponto de vulnerabilidade que pudesse comprometer em absoluto e irremediavelmente a representação do sucessor de D. Dinis. Em contrapartida, depreciar momentaneamente a imagem do infante para exaltar a figura do rei de Portugal e protagonista da crônica revela-se, se não vantajoso para Afonso ao menos útil para a memória do reino e de seu pai.

Houvesse ou não razão para os supostos ciúmes, invejas e desconfianças do herdeiro do trono face aos bastardos régios expressos na primeira causa, os outros dois motivos apontados na crônica para uma revolta do infante possuem, de acordo com o historiador lusitano Bernardo Vasconcelos e Sousa, uma ressonância mais pragmática. Afinal, as "riquezas" da coroa mostravam-se apetecíveis não somente para Afonso - que recebeu consideráveis quantias por mais de uma vez nas tréguas celebradas com o pai - mas também para aqueles que seguiam o futuro rei. Por outro lado, o exercício da "Justiça" evocado tanto no fragmento quanto em diversas crônicas régias constituía uma das principais características do poder de um soberano, ganhando assim na reivindicação do infante um significado político (Sousa, 2009, p. 46).

Parecendo reproduzir parte do discurso contido nas crônicas, Vasconcelos e Sousa presume que a vida de Afonso foi bastante preenchida e agitada, com uma juventude e um início de idade adulta de grande irrequietude e rebeldia. $\mathrm{O}$ infante pegaria várias vezes em armas contra seu próprio pai, encabeçando a revolta de nobres que enfrentavam a política centralizadora do monarca (Sousa, 2009, capa).

O historiador Georges Duby sublinha que, a partir do século XI, a Igreja consegue colocar a sexualidade sob seus cuidados, o que posteriormente viria a ser reforçado com o já citado IV Concílio de Latrão. Ela regia a instituição matrimonial, não somente impondo uma moral do casamento, mas também dirigindo a consciência feminina em prol de seus maridos. Concentrando-se na tentativa de estabelecer uma genealogia - uma origem - dos pecados e das punições das mulheres, Duby cita o bispo de

\footnotetext{
${ }^{13}$ Sobre os princípios do poder real na Idade Média ver: Le Goff, J. Rei. In: Le Goff, J. E Schmitt, 2002, p. 400-401.
} 
Rennes, Étienne, que, no século XII, compara o ritual do casamento ao da vassalagem, nos quais mulher e vassalo exprimem suas obrigações: servir e aconselhar o homem lealmente, sem mentir. $O$ esposo, tal qual o senhor na relação vassálica, deve proteção e assistência (Duby, 2001, p. 39). ${ }^{14}$

Em seus estudos sobre a Idade Média, Silvana Vecchio resumiu os deveres do marido em uma tríade presente nos discursos pastorais acerca do matrimônio: sustento, instrução e correção. Acima de tudo, o homem tem a obrigação de manter a esposa e, num sentido mais amplo, garantir a ela ornamentos e vestuário de acordo com sua condição. Já a função pedagógica implica que a mulher deve aprender tudo do marido. Em primeiro lugar, ele deve lhe ensinar a economia doméstica, dando-Ihe condições de administrar a casa e os bens. Mas deve, sobretudo, tratar de sua instrução moral e religiosa, controlando seus costumes. Quanto à repreensão da mulher, deve-se ter em conta que o comportamento do marido não deve ser demasiado severo, pois a austeridade excessiva é um dos mais graves defeitos dos homens e causa de fortes perturbações da paz familiar (Vecchio, 1990, pp. 159-161).

Ao analisar a inserção dos estudos de Duby, Vecchio e outros sobre as mulheres do período medieval ou a relação entre os sexos feminino e masculino nesse período histórico, em meio às discussões gerais concernentes à História das Mulheres e à História de Gênero, nota-se que, apesar das particularidades temporais e espaciais de cada pesquisa, a diferença sexual inscreve-se nas práticas e nos fatos, organizando a realidade e o cotidiano. Segundo Roger Chartier, ela é sempre constituída por um discurso que a funda e legitima (Chartier, 1995, p. 43).

Nesse sentido, Joan Scott aponta que é fundamental perceber como as sociedades representam os gêneros e os utilizam para articular regras de relações sociais. Assim, a categoria gênero estabelece significados para as diferenças sexuais, ou seja, é "uma forma de indicar 'construções culturais' - a criação inteiramente social de ideias sobre os papeis adequados aos homens e às mulheres" (Scott, 1995, p. 75).

Nascido dos usos e significados de disputas políticas - que são os meios pelos

\footnotetext{
${ }^{14}$ Carla Casagrande também identifica em alguns sermões e tratados a necessidade de uma atitude protetora em relação ao feminino: a palavra "custódia" utilizada pela autora significa tudo aquilo que pode e deve ser feito para educar as mulheres nos bons costumes e salvar suas almas, como reprimir, vigiar, encerrar, mas também proteger, preservar, cuidar. Assim, as mulheres guardadas são protegidas como um bem inestimável e vigiadas como um perigo sempre imanente. Casagrande, 1990, p. 121.
} 
quais as relações de poder, dominação e subordinação são construídas - o gênero não se refere apenas a ideias, mas também a instituições e estruturas práticas cotidianas e rituais específicos, já que todas constituem relações sociais (Scott, 1994, pp. 12-13). A categoria é, assim, um aspecto geral da organização social, que pode ser encontrado em muitos lugares, já que os significados da diferença sexual são invocados e disputados como parte de muitos tipos de lutas pelo poder (Scott, 1994, p. 20).

Nos textos medievais, em sua maioria escritos por homens e influenciados pela tradição patrística da Antiguidade Tardia, ${ }^{15}$ entende-se que o gênero está marcadamente presente quando os autores se referem às relações entre homens e mulheres em seus contextos ou se propõem a elaborar modelos de comportamento para os dois sexos. Além disso, conforme atesta Carolina Fortes, as identidades de gênero constroem-se uma com relação à outra, dado a mentalidade da própria sociedade medieval. Sem dúvida, a categoria gênero pode ser utilizada para o estudo da Idade Média também como uma forma de exprimir as relações de poder (Fortes, 2004, pp. 54 e 59). E, aqui, poder significa sujeitar-se, não existindo sem súditos - isso é, sem submetidos concretamente designados por referenciais objetivos, reais ou simbólicos (Sousa, 1992, p. 509). Concorda-se, portanto, com a reflexão de Armindo de Sousa sobre o termo, concebido por:

Sujeitar, portanto. O que quer dizer coagir, forçar, impor. [...], com efeito, a imposição de comportamentos e valores mediante a socialização, sejam quais forem os seus mecanismos, é modo de coagir e forçar, psicopedagógico é certo, subtil, mas maneira de contrariar o curso da natureza, o qual se pressupõe diferente e oposto à vontade de quem decide sobre quais são os "bons comportamentos" e "bons valores sociais" (Sousa, 1992, p. 510).

\footnotetext{
${ }^{15}$ A reflexão ocidental sobre a diferença dos sexos em favor do masculino é antecedente ao período medieval. Desde os primeiros Pais da Igreja, uma série de interpretações de textos bíblicos foi elaborada por autores como Jerônimo e Agostinho e retomada ao longo dos séculos a fim de defender a supremacia masculina. Em tal discurso, as histórias da Tentação e da Queda justificariam a dominação do homem, já que Eva, a primeira mulher, teria sucumbido após ser seduzida pela serpente, carregando em si a maldição divina. Assim, a mulher seria caracterizada por uma inferioridade natural em teoria e que ocuparia uma posição secundária no que diz respeito ao homem. De acordo com os pensamentos de Agostinho formulados por volta do final do século IV, por exemplo, Deus havia criado Eva após o homem para ajudá-lo na reprodução e multiplicação da espécie. Tal qualidade de auxílio feminino resulta inclusive na subordinação da mulher na relação conjugal, na qual a obediência da mesma tornase o fundamento da harmonia do casal. Desse jeito, incorporava-se hierarquia à união. Sobre mais detalhes referentes às prerrogativas agostinianas e outras posteriores, ver Klapisch-Zuber, 2002, p. 137143.
} 
Apropriando essa maneira de ditar regras sociais ao período medieval e à categoria gênero, tem-se que:

Na Idade Média não se concebe a ordem sem hierarquia. A construção do masculino/feminino no período respeita esta noção e se esforça em articular entre eles os dois princípios da polaridade e da superposição hierarquizada, quer dizer, uma classificação binária e horizontal fundamentada na oposição, e uma interdependência vertical entre categorias. Desta difícil combinação resulta uma imagem negativa e inferior do feminino na sua relação com o masculino. Mas esta imagem também é ambivalente, já que a ideia de complementaridade dentro de uma globalidade resta subjacente às classificações por categorias e por oposição (Klapisch-Zuber, 2002, p. 139).

Tanto a concepção de poder compartilhada por Sousa quanto a lógica da relação entre o feminino e o masculino indicada por Fortes e Zuber aplicam-se inclusive ao matrimônio dos infantes. Beatriz de Castela possuiria a qualidade da subserviência ao estar presente nos projetos de Afonso contra seu pai. Embora Ana Rodrigues afirme que a castelhana não concordava "com sua postura violenta" (Oliveira, 2010, p. 222), não foi encontrada nas crônicas portuguesas qualquer manifestação de discordância aberta da esposa diante do embate com o rei D. Dinis. Dessa forma, Beatriz também parecia ter um comportamento de essencial interesse com relação às mulheres do baixo medievo - e principalmente às rainhas enquanto modelos em seu reino - de moderação no uso da palavra. Segundo os pregadores e moralistas pesquisados por Carla Casagrande, as mulheres falam demais e mal, mentem com habilidade, trocam maledicências, discutem continuamente, são insistentes e lamuriosas. Pior do que isso:

Esta imoderada e perversa tagarelice, além de ser individualizada como fonte de desordem no seio da comunidade familiar e social, representa também um sério risco para a castidade feminina, nunca suficientemente controlada. Uma mulher demasiado loquaz é, na realidade, uma mulher demasiado voltada para o exterior e demasiado desejosa de tecer, com as suas palavras, relações sociais de vários tipos (Casagrande, 1990, p. 134).

A concepção negativa da palavra feminina implica então na necessidade de sua custódia, pois a palavra é de fato um poder e privilégio que os homens desejam deter com exclusividade. Nesse sentido, as palavras do juízo, do poder, da cultura e da salva- 
ção devem se manter sob posse masculina (mas há que considerar as exceções da concessão da palavra às mulheres, tal qual o caso das abadessas que presidem comunidades monásticas e de mulheres aristocráticas, que na ausência ou morte do marido comandam seus domínios).

A relação conjugal de Beatriz e Afonso fora descrita com características semeIhantes às analogias de Étienne e às fontes analisadas por Vecchio e Casagrande, não somente pela parte de Beatriz enquanto esposa transigente e de fala moderada, mas inclusive pelo cumprimento da função protetora de Afonso como marido e homem na medida em que o masculino era entendido como a criatura dotada de coragem, bravura, insensibilidade diante da dor e a ele cabia ensinar, pregar, tutelar os mais fracos, protegendo-Ihes e garantindo-Ihes segurança (Fortes, 2004, p. 148) - conforme se pode perceber, em 1320, na tentativa do infante de afastar a esposa do conflito:

Como ho Ifante foi em Coimbra, logo levou sua molher, e filhos a Alcanizes, que hee em Castella, ho quaal tinha hum Fernam Martins Dafoncequa, e ali ha deixou acompanhada dalguns Escudeiros, e se tornou pera Coimbra, onde por suas cartas cheias de piedades, e palavras, promessas, e necessidades, que apontou logo fez chamamento de todos seus vassallos, e servidores dizendo, que o socorressem, porque ElRei queria vir sobrelle, e destroilo, ou matalo, sem causa (Pina, 1912, vol. 2, p. 130).

Esse ato antecedeu o apelo à mobilização geral dos "vassalos" e "servidores" do herdeiro da coroa com o argumento de que o rei se preparava para investir militarmente contra ele. Vasconcelos e Sousa inclusive infere que foi essa "escalada no conflito" que levou o monarca a tornar público, por meio de cartas que mandou difundir pelo reino, que, dali em diante, aqueles que apoiassem o infante seriam acusados de crime de traição (Sousa, 2009, p. 54).

Vê-se, portanto, que a relação conjugal de Afonso e Beatriz incluiria traços de cumplicidade e de proteção que contribuiriam para a propagação de uma imagem medieval de casamento profícuo, reforçada particularmente pela ausência de filhos bastardos após a realização do matrimônio (Lourenço, 2008, p. 356). Ademais, apesar de a infidelidade masculina - se comparada à feminina - ser praticada sem grandes conse- 
quências na Idade Média, ${ }^{16}$ ela era indesejável aos homens que serviam de exemplo à sociedade (reis e príncipes, especialmente) e não parecia ser praticada por D. Afonso IV. Mais do que qualquer outro casal, o rei e a rainha precisavam se pautar nos bons e virtuosos comportamentos, pois eram exemplo maior das relações conjugais em seu reino.

No caso específico de Beatriz de Castela e seu marido, existem duas hipóteses para a inexistência de bastardos. A primeira consiste na convivência dos esposos, baseada na construção de laços de amizade desde o período da infância, já que Beatriz foi para Portugal com apenas quatro anos de idade. A segunda, por sua vez, remete-se à tentativa de Afonso em evitar que seus herdeiros legítimos passassem pelos mesmos problemas sofridos por ele (Oliveira, 2010, p. 217).

Embora em meados e finais da Idade Média, a união conjugal tenha se tornado mais sacramental aos olhos dos teólogos - a fidelidade, por exemplo, passa a ser valorizada como obrigação mútua do casal pela literatura teológica e pastoral (Vecchio, 1990, p. 152) - haverá dissonâncias. Gilberto de Tournai e outros insistem sobre a reciprocidade da obrigação, mas lembram que muitos maridos pensam injustamente estarem menos vinculados à fidelidade do que as esposas. Para Tiago de Varazze, a fidelidade também é vista como dever recíproco, mas o dominicano acaba por reconhecer que a mulher guarda a fidelidade melhor que o marido, pois é controlada por quatro custódias: temor a Deus, controle pelo marido, vergonha, medo das leis. Assim, a fidelidade como sendo mais necessária às mulheres do que aos homens torna-se evidente em textos de inspiração aristotélica e na literatura teológico-moral que debate o adultério (Vecchio, 1990, pp. 151-152). Conforme Jacques Rossiaud:

[...] as sociedades medievais viveram sob uma moral sexual dual, atribuindo ao homem todas as liberdades aferentes à superioridade de seu sexo e reservando à mulher a modéstia. Uma mulher [...] não podia encarar uma relação sexual normal sem recear as consequências comuns: a desonra para as donzelas e/ou a fadiga de gravidezes sucessivas e de partos perigosos (Rossiaud, 2002, p. 483).

A Igreja procurava impor a indissolubilidade do matrimônio, bem como estabe-

\footnotetext{
${ }^{16}$ Analisando processos do tribunal eclesiástico da Paris medieval, Opitz argumenta que "[...] enquanto as normas jurídicas e a mentalidade pretendiam condenar as mulheres adúlteras com a pena de morte, os homens casados com o mesmo comportamento escapavam impunes". Opitz, 1990, p. 369.
} 
lecer os fundamentos da união cristã. Então, o que passava a caracterizar a união conjugal na Idade Média de acordo com a instituição eclesiástica eram os filhos comuns e a fidelidade conjugal (Opitz, 1990, pp. 374-375). Segundo os textos medievais com propósito moral e pedagógico estudados por Carla Casagrande, as mulheres casadas deviam viver virtuosamente sua sexualidade no interior do matrimônio e precisavam manter suas intenções puras e castas, voltadas somente ao cumprimento do dever conjugal e propagação da espécie (Casagrande, 1990, pp. 99-141). A fidelidade conjugal, já debatida anteriormente, afirma-se então no medievo como uma característica essencial e indispensável à mulher casada, pois é garantia da legitimidade da descendência (Vecchio, 1990, p. 152).

Embora no casamento de Beatriz de Castela e D. Afonso IV não tenha havido bastardos e tenha gerado muitos filhos, as relações diplomáticas entre Portugal e Castela nos séculos XIII e XIV não se revelavam muito sólidas. Nesse sentido, nem sempre uma consistente união matrimonial entre membros de realezas significava e garantia a continuidade de acordos e alianças. Mesmo chegando a Portugal bastante jovem, a familiaridade de Beatriz aos costumes lusitanos e a afinidade com os membros da corte derivadas de uma longa convivência não foram suficientes para impedir a existência de atritos entre, por exemplo, seu marido e seu sobrinho Afonso XI de Castela. ${ }^{17}$

Contudo, na vinda de Beatriz, a Crônica de D. Dinis ressalta a imagem dos portugueses como bons anfitriões, como se Rui de Pina cobiçasse propagar a ideia de uma corte hospitaleira e próspera. Cabe igualmente notar a maneira como o autor descreve o momento do matrimônio da castelhana, conforme o fragmento a seguir:

E depois ho dito Ifante recebeo por palavras de prezente a Ifante sua molher, e se fizeraõ suas festas, e vodas em Lixboa, e ElRei Ihe deu Vianna, e Terena e ho Castello Dourem, e ha terra Darmamar junto de Lamego, e ha sua molher muitas teerras, e grandes joias, e riquezas, como aho diante se diraa (Pina, 1912, vol. 1, p. 65).

Acima, a ênfase é dada mais à generosidade do rei D. Dinis - ao ofertar inúmeros presentes como terras e joias - do que ao casamento dos infantes. Ademais, em-

\footnotetext{
${ }^{17}$ Faz-se alusão indireta especialmente ao período entre 1336 e 1339, no qual, por três anos de guerra luso-castelhana, houve invasões mútuas e destruição para os dois lados. Cabe lembrar que foi na mesma época que a Guerra dos Cem Anos eclodiu oficialmente, afastando cada vez mais os reinos em blocos distintos.
} 
bora Pina tenha feito referências a outras passagens da crônica que abordam o assunto, a proeminência do protagonista permaneceria em sua forma de escrita:

Atraaz fica escrito has dificuldades, e trabalhos com que ElRei D. Diniz cazou o Ifante D. Affonso seu filho, com ha Ifante Dona Breatiz, filha delRei D. Sancho de Castella, e por Ihe teer grande amor, e afeiçaõ como ha rezaõ requeria, Ihe deu sua caza em Lixboa, com muitas, e graãdes festas, pera que de seus poovos ouve grandes ajudas, [...] (Pina, 1912, vol. 2, p. 107).

No fragmento, a centralidade de D. Dinis não se dava somente por ser pai e rei, mas sim por sê-lo com "grande amor", "afeição" e principalmente "razão". Essas virtudes aparecem simbolicamente reconhecidas pelo "povo" na medida em que esse fornece "ajudas" ao monarca, figura central da trama. Afinal, Carolina Fortes lembra que o principal atributo do homem é a ação; ele é sempre ator e governado pela razão (Fortes, 2004, p. 148). Na medida em que o agente passa a ser o rei, maximiza-se então seu poder de ação e seu protagonismo.

Rita Costa Gomes sinaliza as cerimônias régias como um dos principais mecanismos de poder no final da Idade Média. Como ressalta a autora, a ação ritual não seria somente uma representação do poder, mas o objeto próprio da cerimônia, sua eficácia e o seu fim (Gomes, 1995, p. 297). Cabe remeter-se também a Georges Balandier quando escreve que "o grande ator político comanda o real através do imaginário" (Balandier, 1982, p. 6), ou seja, a afirmação de um monarca não se dá apenas pelo poder determinado por violência ou força, mas pela "[...] produção de imagens, pela manipulação de símbolos e sua organização em um quadro cerimonial" (Balandier, 1982, p. 7). Aqui, a corte cumpre a função de permitir a encenação do poder, sendo o teatro do príncipe justificado pela própria hierarquia celestial:

Como Deus na corte celeste, o rei devia aparecer na sua corte em todo seu esplendor, no cume de uma longa hierarquia rigorosamente ordenada. E quanto mais o tempo passava, mais crescia a distância entre o príncipe e os que o cercavam. [...] Não somente esses eventos [coroamento do príncipe, seu casamento, seus funerais, os batismos de seus filhos] eram ordenados por um cerimonial cada vez mais rígido, como cada momento da vida do príncipe era devidamente regulado. Uma simples refeição tornava-se um ritual (Guenée, 2002, pp. 278-279). 
Nesse sentido, a boda pública régia medieval expressa por meio da literatura portuguesa cumpre perfeitamente a função de teatralização do poder ao constituir-se em meio espetacular. Fica evidente, portanto, o papel do rei D. Dinis como grande articulador da boda de seu filho, herdeiro do trono, garantindo legitimidade e continuidade à dinastia através de uma cerimônia pública. Le Goff, por exemplo, destaca que "o rei [medieval] também é um rei cerimonial, como testemunham o simbolismo e o ritual régios" (Le Goff, 2002, p. 402). Nieto Soria igualmente reconhece as relações entre os ritos e a questão do poder (Nieto Soria, 1993, pp. 16-17). Importa ressaltar, porém, que a masculinidade régia se constrói a partir de um modelo normativo e narrativo hegemônico no Ocidente, pautado essencialmente pelos princípios cristãos e os valores da nobreza laica.

Assim, apesar de apresentar uma tipologia de escrita menos minuciosa que o conhecido cronista português Fernão Lopes, Rui de Pina narra um casamento régio conforme as regras de época. Isso se confirma até mesmo pela necessidade de autorização papal para, por exemplo, uma dispensa de parentesco, visto que se trata de uma solicitação recorrente nas cortes europeias para garantir tanto a validade do acordo matrimonial quanto a tentativa de segurança em um pacto político. O papel da Igreja em tal matrimônio, portanto, consistia em dar reconhecimento às relações conjugais evidente que recebendo benefícios em troca - perante uma comunidade cristã.

\section{Fonte}

PINA, R. 1912. Chronica d'El-Rei D. Diniz. 2 ed. Lisboa, Escriptorio (Coleção Bibliotheca de Classicos Portuguezes), 1912, 2 volumes.

\section{REFERÊNCIAS}

ALMEIDA, F. 1967. História da Igreja em Portugal. 2 ed. Porto, Portucalense Editora, vol. 1, $2355 \mathrm{p}$.

BALANDIER, G. 1982. O Poder em Cena. Brasília: Editora Universidade de Brasília, 78 p. BARROS, H. G. 1885. História da Administração Pública em Portugal nos séculos XII a $X V$. Lisboa, Imprensa Nacional, Tomo I.

BASCHET, J. 2006. A civilização feudal: do ano mil à colonização da América. São Paulo, Globo, $584 \mathrm{p}$.

BROOKE, C. 1989. O casamento na Idade Média. Lisboa, Publicações Europa-América, $268 \mathrm{p.}$

CAETANO, M. 1985. História do Direito Português (1140-1495). Lisboa, Verbo, 591 p. 
CASAGRANDE, C. 1990. A mulher sob custódia. In: DUBY, G. e PERROT, M. (orgs.). História das mulheres no Ocidente. Volume 2: "A Idade Média". Porto, Edições Afrontamento, pp. 99-141.

CHARTIER, Roger. 1995. Diferenças entre os sexos e dominação simbólica. Cadernos Pagu, Campinas, vol. 4, pp. 37-47.

DUBY, G. 2001. Eva e os padres: damas do século XII. São Paulo: Companhia das Letras, $176 \mathrm{p}$.

FORTES, C. C. 2004. Os Atributos Masculinos das Santas na Legenda Áurea: os casos de Maria e Madalena. Rio de Janeiro, RJ. Dissertação (Mestrado em História Social), Universidade Federal do Rio de Janeiro, $279 \mathrm{p}$.

FUENTE, M. J. 2004. Reinas medievales: en los reinos hispânicos. Madrid, La Esfera de Los Libros, $471 \mathrm{p}$.

GARCÍA, M. I. L. 2001. Sistemas de parentesco y estructuras familiares en la Edad Media. In: DUARTE, J. I. I. (coord.). La familia en la Edad media: XI Semana de Estudios Medievales, Nájera. Disponível em: http://dialnet.unirioja.es/servlet/articu lo?codigo=595373. Acesso em: 28/08/2015.

GIMENEZ, J. C. 2012. Reinos em guerras, infantas aflitas: a mulher nas vicissitudes políticas das monarquias ibéricas medievais. Revista Diálogos Mediterrânicos, Curitiba, $\mathrm{n}$. 2, mai. 2012, pp. 98-109.

GOMES, R. C. 1995. A Corte dos Reis de Portugal no Final da Idade Média. S/I, DIFEL, $383 \mathrm{p}$.

GUENÉE, B. 1981. O Ocidente nos Séculos XIV e XV: os Estados. São Paulo, Pioneira, 1981, 281 p.

. 2002. Corte. In: LE GOFF, J. e SCHMITT, J. C. (orgs.). Dicionário Temático do Ocidente Medieval. Bauru, EDUSC, vol. 1, pp. 269-280.

GUERREAU-JALABERT, A. 2002. Parentesco. In: LE GOFF, J. e SCHMITT, J. C. (orgs.). Dicionário Temático do Ocidente Medieval. Bauru, EDUSC, vol. 2, pp. 321-336.

KLAPISCH-ZUBER, C. 2002. Masculino/feminino. In: LE GOFF, J.e SCHMITT, J. C. (orgs.). Dicionário Temático do Ocidente Medieval. Bauru, EDUSC, vol. 2, pp. 137-143.

LE GOFF, J. 2002. Rei. In: LE GOFF, J. e SCHMITT, J. C. (orgs.). Dicionário Temático do Ocidente Medieval. Bauru, EDUSC, vol. 2, pp. 395-414.

LOURENÇO, V. 2008. Carta de arras da rainha D. Beatriz (1309-1359). Estudios Humanísticos: Historia, Leão, n. 7, pp. 349-358.

MELLO, I. A. 2006. Memória e Identidade nas Cerimônias e Rituais Régios da Dinastia Portuguesa de Avis (1481-1495): uma análise da influência do movimento da Nova História na Historiografia Ibérica. Anais do XVIII Encontro Regional de História: O historiador e seu tempo. São Paulo. Disponível em: http://www.anpuhsp.org.br/sp/down loads/CD\%20XVIII/pdf/ST\%2013/leda\%20Av\%EAnia\%20de\%20Mello.pdf. Acesso em: $30 / 12 / 2017$.

NIETO SORIA, J. M. 1993. Cerimonias de la realeza: Propaganda e legitimación en la Castilla Trastámara. Madrid, NEREA, 278 p.

OLIVEIRA, A. R. 2010. Rainhas medievais de Portugal: dezessete mulheres, duas dinastias, quatro séculos de História. Lisboa, Esfera dos Livros, 678 p.

OLIVEIRA MARQUES, A. H. 1987. Portugal na Crise dos séculos XIV e XV. In: SERRÃO, J. e OLIVEIRA MARQUES, A. H. (dir.). Nova História de Portugal. Lisboa, Presença, vol. 4, $664 \mathrm{p}$.

OPITZ, C. 1990. O quotidiano da mulher no final da Idade Média (1250-1500). In: DUBY, 
G. e PERROT, M. (orgs.). História das mulheres no Ocidente. Volume 2: "A Idade Média". Porto, Edições Afrontamento, pp. 362-375.

OSÓRIO, J. 1993. D. Dinis: o rei, a língua e o reino. Máthesis, Viseu, n. 2, pp. 17-36.

ROSSIAUD, J. 2002. Sexualidade. In: LE GOFF, J. e SCHMITT, J. C. (orgs.). Dicionário Temático do Ocidente Medieval. Bauru: EDUSC, vol. 2, pp. 477-493.

SCOTT, J. W. 1994. Prefácio à Gender and Politcs of History. Cadernos Pagu, Campinas, vol. 3, pp. 11-27.

1995. Gênero: uma categoria útil de análise histórica. Revista Educação \& Realidade, Porto Alegre, v. 20, n. 2, pp. 71-99.

SCHMITT, J. C. 2002. Imagens. In: LE GOFF, J. e SCHMITT, J. C. (orgs.). Dicionário Temático do Ocidente Medieval. Bauru, EDUSC, vol. 1, pp. 591-605.

SERRÃO, J. (dir.). 1984. Dicionário de História de Portugal. Porto, Figueirinhas, vol. 1.

SOUSA, A. 1992. A Monarquia Feudal. In: MATTOSO, J. (dir.). História de Portugal. Lisboa, Estampa, vol. 2, 560 p.

SOUSA, B. V. 2009. D. Afonso IV. Lisboa, Círculo de Leitores (Coleção Reis de Portugal), $368 \mathrm{p}$.

TREVISAN, M. B. 2012. Construção de identidades de gênero e afirmação régia: os casais da realeza portuguesa entre os séculos XIV e XV a partir das crônicas de Fernão Lopes. Niterói, RJ. Dissertação (Mestrado em História Social), Universidade Federal Fluminense, $272 \mathrm{p}$.

VECCHIO, S. 1990. A boa esposa. In: DUBY, G. e PERROT, M. (orgs.). História das mulheres no Ocidente. Volume 2: "A Idade Média". Porto, Edições Afrontamento, pp. 152165. 